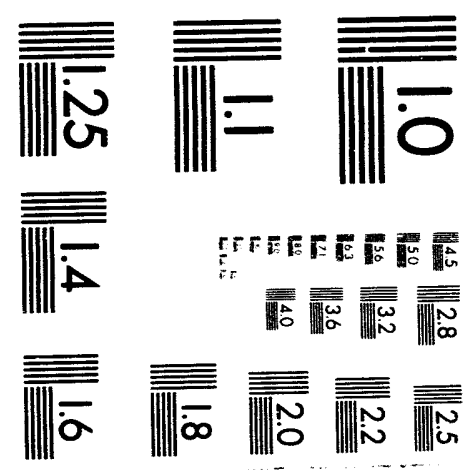



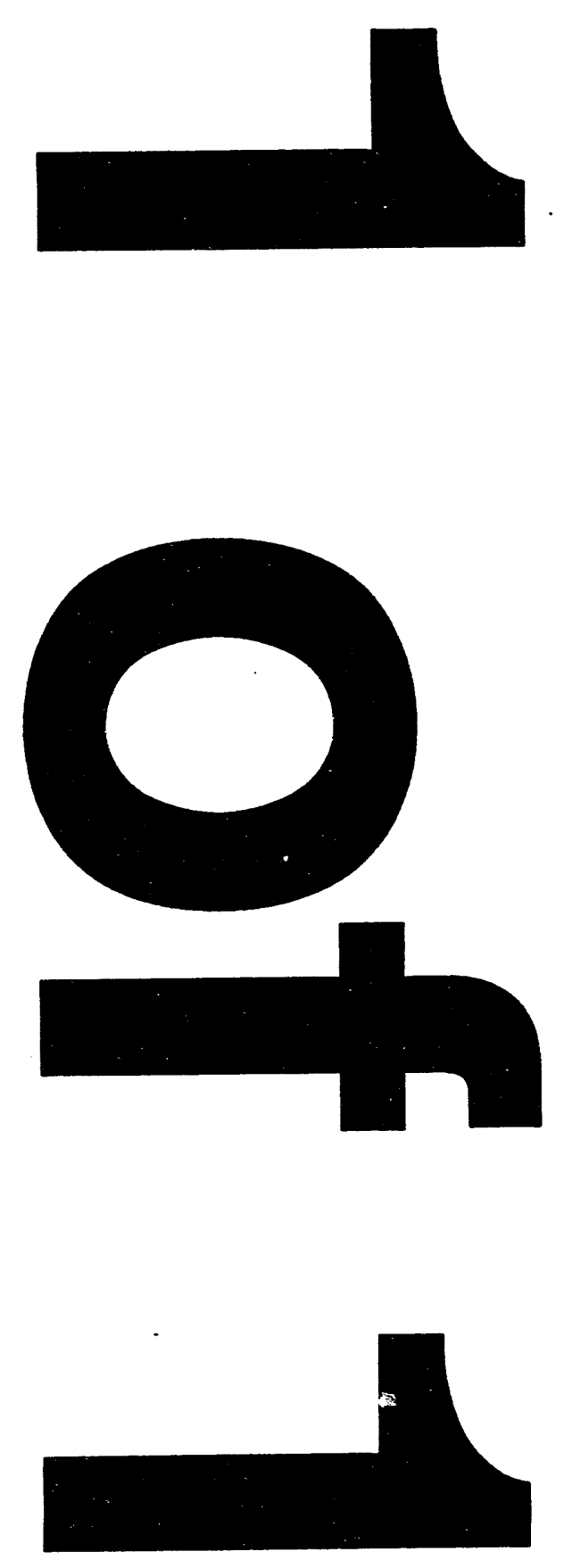
$\operatorname{couf}-7.31108--5,5$

UCRL-JC-114122

PREPRINT

\title{
INTRODUCED MATERIALS AND COLLOID FORMATION: A REPORT ON THE CURRENT STATE OF KNOWLEDGE
}

\author{
A. Meike \\ C. Wittwer
}

This paper was prepared for submittal to the Materials Research Society

Boston, MA

November 29-December 3, 1993

November 1993
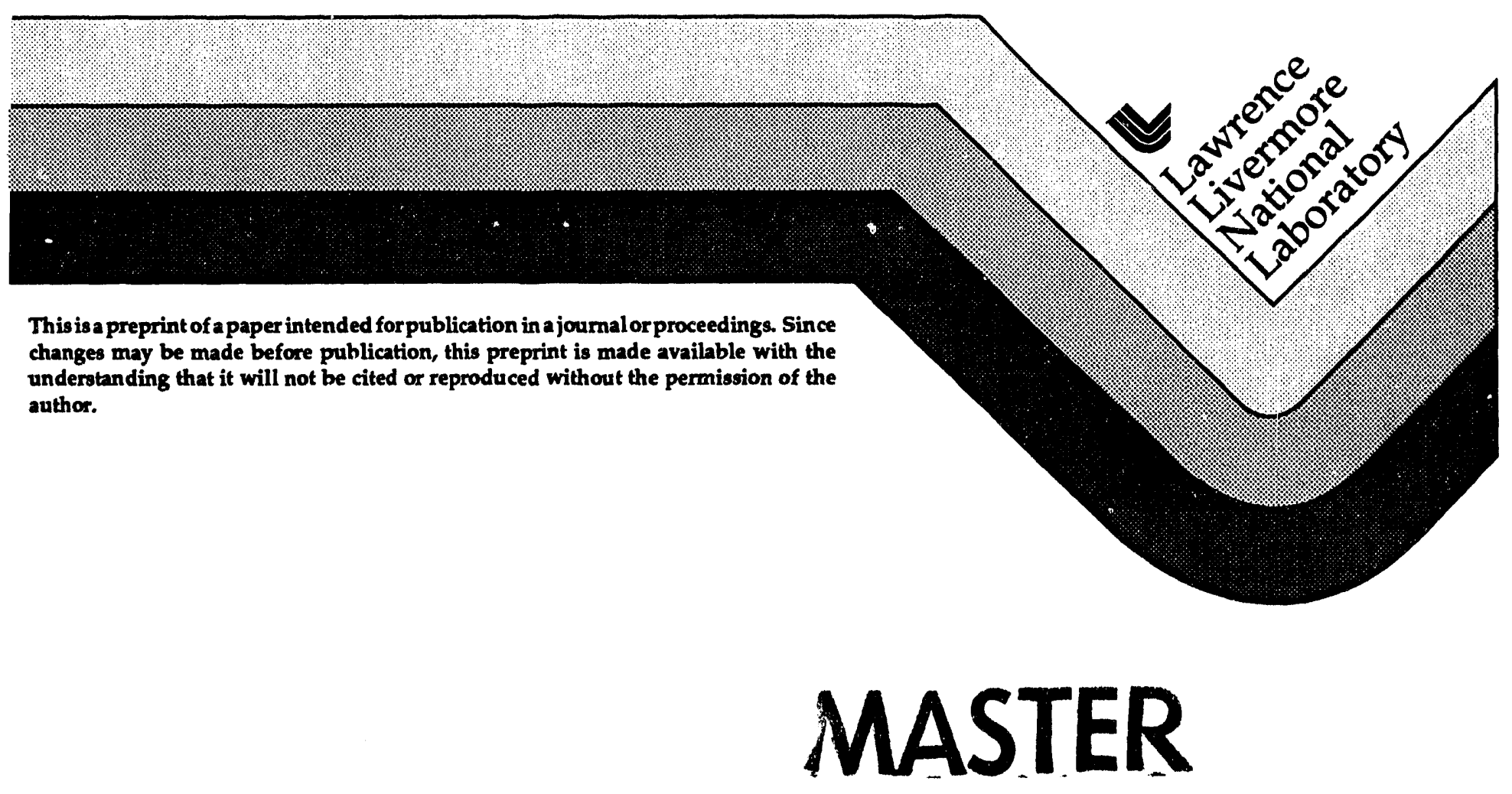


\section{DISCLAIMER}

This document was prepared as an account of work sponsored by an agency of the United States Government. Neither the United States Government nor the University of California nor any of their employees, makes any warranty, express or implied, or assumes any legal liability or responsibility for the accuracy, completeness, or usefulness of any information, apparatus, product, or process disclosed, or represents that its use would not infringe privately owned rights. Reference herein to any specific commercial products, process, or service by trade name, trademark, manufacturer, or otherwise, does not necessarily constitute or imply its endorsement, recommendation, or favoring by the United States Government or the University of California. The views and opinions of authors expressed herein do not necessarily state or reflect those of the United States Government or the University of California, and shall not be used for advertising or product endorsement purposes. 


\title{
INTRODUCED MATERIALS AND COLLOID FORMATION: A REPORT ON THE CURRENT STATE OF KNOWLEDGE
}

\author{
A. MEIKE*, AND C. WITTWER ${ }^{* *}$ \\ *Earth Sciences Division, LLNL, PO Box 808 Livermore, California 94550 \\ **BRGM Dépt de l'Eau, Av. de Concyr, BP 6009, 45060 Orléans Cedex 02, France
}

\begin{abstract}
This paper reviews potential sources of colloids and enhanced adsorption of radionuclides that may stem from materials introduced into a repository setting. Three major sources of colloids are examined: metals, cements, and organics. The sensitivity of colloids to chemical species, $\mathrm{pH}$, time, temperature, radiolysis, redox state, gradients of the aforementioned variables, and microbial activity is shown. We consider these influences on colloid formation and sorption with respect to introduced materials. We also discuss areas that have not been addressed but may have consequences in a repository setting.
\end{abstract}

\section{INTRODUCTION}

It has become clear that colloids could play a significant role in the transport of radionuclides from a radioactive waste repository. However, colloid studies rarely consider the large quantities of introduced materials that may form colloids and pseudocolloids (to use the terminology that distinguishes radionuclide species in suspension (the former) from suspended matter that adsorbs radionuclides(the latter)) or enhance the formation or transport of naturally occurring colloids. Given the roughly 430 miles of repository tunnel that could be required by some of the designs for the potential Yucca Mountain repository under consideration at present, the contributions of some of these materials could be significant. For example, the Site Characterization Plan (SCP) design includes approximately $560,000 \mathrm{~m}^{3}$ of shotcrete in the emplacement drifts alone. The exact quantities and types of materials that could be introduced cannot be quantified or identified in the present phase of the potential repository design. However, some important reference points exist, such as the Nevada Nuclear Waste Storage Investigations Exploratory Shaft Facility (ESF) Fluids and Materials Evaluation ${ }^{1}$ and the estimated materials usage at the ESF North Portal Facility for FY93. The estimated usage of some materials in the latter include massive quantities of: water $(21,000,000$ gallons), diesel fuel $\left(250,000\right.$ gallons), rockbolt resin $\left(10,000 \mathrm{lbs}\right.$.), extruded polystyrene $\left(1,800 \mathrm{ft}^{2}\right)$, bentonite clay ( $50 \mathrm{yd}^{3}$ ), and cable lubricant ( 250 gallons).

Interactions between man-made materials and groundwater could lead to the formation of oxyhydroxides, hydroxides and oxides (oxy(hydr)oxides); clays and other polysilicates; and organic particles. Introduced materials can provide many of the anions required to form pseudocolloids (hydroxides, carbonates, phosphates, silicates, and fluorides). Interactions between these materials and groundwater could lead to the formation of colloids that represent the same range of sizes as natural colloids: very small $(<10 \mathrm{~nm}$ ) hydrated metal ions, small organic particles, polyhydroxy-complexes, polysilicates, and fulvic acids; medium sized range (10-100 nm) clays and metal hydroxides; and large ( $>1 \mu \mathrm{m}$ ) inorganic and organic particles. This paper summarizes relationships between colloid particles and chemical and physical changes in the environment in the context of an environment chemically modified by introduced materials as we understand them currently. A more complete review of the literature is presented elsewhere. ${ }^{2}$ 


\section{INTRODUCED MATERIALS AS SOURCES OF COLLOIDS}

Colloids can result from: release from bulk material (by dissolution of matrix, chemical reaction, hydrodynamic force, or mechanical stress), precipitation, microbial activity, or introduction..$^{3-5}$ Clearly, each of these mechanisms applies to some of the potential repository materials. The tendency for colloids to remain suspended is determined by their fundamental characteristics, such as physical size, bulk charge, density, and chemical characteristics (reactivity and structure). These characteristics, in turn, are affected by redox conditions, $\mathrm{pH}$, temperature, ionic strength, organic content, water velocity, and colloid concentration. ${ }^{6}$

Oxyhydroxides. It is possible that iron will be the most abundant metal in the repository. The formation kinetics and stability of ferrihydrite, which is the amorphous form and precursor of the ferric oxyhydroxides, and its transition to goethite and hematite, are extremely dependent on the environment, especially temperature, $\mathrm{pH}$, the presence of species such as fulvic acid and $\mathrm{Si}$, and even the timing of the introduction of these species. ${ }^{7-10}$ The effectiveness of hematite particle coagulation depends on water chemistry. ${ }^{11}$ Metal adsorption onto oxyhydroxides is also controlled by a complex combination of surface properties that are sensitive to temperature, adsorbate concentration, and ionic strength. ${ }^{12-17}$ For example, in general, the adsorption of organic acids onto goethite increases with decreasing $\mathrm{pH}$. However, affinities of the various acids for goethite varies (oxalic $>$ phthalic $>$ salicylic $=$ lactic) ${ }^{18}$ and the resultant adsorption effects are expected to differ significantly.

$\mathrm{Co}, \mathrm{Cr}$ and $\mathrm{Ni}$ will also be present in various forms. The formation of colloidal corrosion products from these metals has been described in detail. ${ }^{19-21}$ Actinides and hydrolyzable elements, such as $\mathrm{Sr}, \mathrm{Pb}$, and $\mathrm{Cu}$, are also likely to form colloids. ${ }^{22}$ Colloidal manganese oxides can form by oxidation of $\mathrm{MnO}_{2}$ or reduction of $\mathrm{MnO}_{4}{ }^{-23}$

Cement. The degradation of cement phases [tricalcium silicate $\left(\mathrm{C}_{3} \mathrm{~S}\right.$ in cement nomenclature) and dicalcium silicate $\left(\mathrm{C}_{2} \mathrm{~S}\right)$ ] allows the formation of calcium silicate hydrate (CSH) colloidal gels. ${ }^{24}$ Since the calcium silicate phases comprise a major part of the cement volume, this contribution could be substantial. Sorption onto cement and onto its corrosion products has been found to be similar, ${ }^{25}$ which suggests in-situ sorption could be as significant as sorption onto cement-derived colloids. If this is true, then the rate of cement degradation not only affects the amount of colloid present, but, beyond a certain threshold time, is directly related to the release of material over time.

The presence of other ions and organic material within or in the proximity of the cement will probably affect cement degradation, the contribution of chemical species to the aqueous state and, thus, the formation of colloids. Materials that comprise a large volume fraction of the final cement product include: silica fume, blast furnace slag (bfs) and other sources of $\mathrm{Si}(\mathrm{OH})_{4}$, ash, iron hydroxides and oxyhydroxides from rebar and wire mesh reinforcements, and sulfate and iron impurities of the cement. Salt solutions, aliphatic aromatics, and saccharides that are added in small concentrations to accelerate or retard hardening, or otherwise modify cement properties could also contribute to colloid formation and adsorption. These effects are as yet poorly understood.

Organics. The degradation of plastics, PVC, cellulose, rubber, and polyethene under chemical and radiolytic attack is expected to give rise to the formation of small water soluble molecules. ${ }^{26,27}$ These molecules can be involved in numerous reactions that directly or indirectly influence the formation and the stability of colloids. These considerations are significant in light of indications that sorption onto colloidal organic matter can be an order of magnitude greater than on soils and sediments. ${ }^{28}$ Thus the 
adsorption of metals, radionuclides, and pollutants on organic colloids could greatly enhance the migration of those species. However, even in the case of humics, which have been studied most intensively, the stability constants, ionic strength and pH effects, competition for metal complexes, and the secondary influence of cation sorption onto minerals are not understood well enough to predict their effect on ion migration. ${ }^{29}$ The behavior of other organic compounds such as EDTA, salicylic and phthalic acids cannot be extrapolated from humic and fulvic acids. The impact of immiscible organic liquids is unknown at present. ${ }^{30}$

The formation and stability of organic-metal and organic-radionuclide complexes depend on multiple and interdependent factors that include the type and concentration of organic matter, the type and oxidation state of the ions and their ionic strength, the $\mathrm{pH}$, and the temperature. $26,29,31,32$ Adsorbed onto hydroxyl groups, organic matter can provide new functional groups (carboxyl, phenolic) for complexation with metals. ${ }^{33}$ Organic films on inorganic surfaces have also been reported to modify trace element mobility. 34

\section{INFLUENCES ON COLLOID FORMATION AND SORPTION}

Radiocolloid and pseudocolloid formation, stability, and sorption are influenced by factors that include: chemical element solubilities, $\mathrm{pH}$, redox state, and ionic strength. $22,24,35-39$ These factors could be modified, or even dominated by introduced materials. The current state of knowledge with respect to these factors and their implications for introduced materials is discussed below.

Gradients. The significance of gradients becomes clear in considering the inhomogeneous distribution of materials that results from emplacement in a repository. Changes in $\mathrm{pH}$, ionic composition, $\mathrm{Eh}, \mathrm{CO}_{2}$ partial pressure, temperature, radiation, bacterial activity, dissolution of introduced material, and contaminant and drilling fluid infiltration can be responsible for colloid precipitation. Changes in redox conditions due to the introduction of reducing compounds [e.g. dissolved organic carbon (DOC)] can cause colloid formation. For example, the adsorption of redox-sensitive elements onto iron and manganese oxides can slow or inhibit changes due to redox conditions. ${ }^{40,41}$ More specific to the potential repository, the effect of $\mathrm{pH}$ and Eh gradients as water percolates from cement into the re rository rock is not well understood. It is thought, however, that the former should favor the formation of hydroxides.

$p H$ and redox state. The relationship between $\mathrm{pH}$ and colloidal silica is complex. ${ }^{42,43}$ Therefore $\mathrm{pH}$ changes caused by man-made materials may impact the formation of colloidal $\mathrm{Si}$. High $\mathrm{pH}$ and low redox conditions are expected from the degradation of cement and from canister corrosion. It is thought that radionuclide species with oxidation states (III) and (IV) will be favored by the low redox conditions. However, a gradient in redox potential may favor the formation of higher oxidation states and more soluble species, thereby limiting the formation of real colloids or polynuclear species while favoring the association of soluble nuclides with pseudocolloids. The influence of changes in redox conditions related to thermal conditions over time and in space needs to be studied.

Temperature. The effect of a thermal pulse due to the emplacement of waste on colloids is unknown. Reduction of solubility with temperature appears to be responsible for increased sorption, but the behavior of radionuclides is also dependent on the type of species and the temperature range. ${ }^{32}$ For example, soluble oxidized species of $\mathrm{Pu}, \mathrm{Tc}$, and $\mathrm{Np}$ can possibly form at high temperature. ${ }^{42} \mathrm{On}$ the other hand, a temperature decrease associated with a return to natural conditions could cause hydrolysis and precipitation of a colloidal solid phase. The stability of radionuclide-organic complexes with temperature also needs to be investigated. ${ }^{32}$ The coupled effects of temperature ( 25 to $80^{\circ} \mathrm{C}$ ), ionic strength and $\mathrm{pH}$ have been reported for hematite sorbed on steel ${ }^{45}$. 
Time. Experimental difficulties have limited the available information about the behavior of organic or inorganic colloids and the mechanisms of sorption and formation over time. In this case, analogs are an invaluable resource. A few references exist for humic substances, but the results appear to conflict. No difference between fresh and old humic substances was observed by Petersson ${ }^{46}$, even though Avogadro and de Marsily ${ }^{44}$ noted that aggregation and size distribution should be enhanced with time. Polymerization and reduction in carbonyl group content during diagenesis were also inferred to cause a reduction in solubility of humic substances. ${ }^{47}$ Desorption has also been observed also in long-term experiments. ${ }^{48}$ Colloid stability also depends on physical adhesion to the medium, which is found to increase over time for some substances. ${ }^{49}$ Thus, data are needed not only for the chemical factors of colloid formation and stability, but also for physical processes over time.

Radiolysis. Only a few authors have considered the possible effect of radiolysis on the formation of colloids. Beyond the observation that more soluble high oxidation states of some radionuclides ( $\mathrm{Tc}, \mathrm{Np}, \mathrm{Pu}$ ) could be favored by radiolysis, ${ }^{44}$ this effect needs to be addressed because it could strongly increase the solubility of compounds that would otherwise be less available for colloid formation. ${ }^{26}$ Examples include the degradation of organic products and the release of small water soluble molecules from rubber, polyethene, and PVC.

Microbial Activity. Microbial activity can cause dissolution, deflocculation, and colloid formation. $24,40,50$ For example, organic substances that usually have low solubility can be solubilized by microbial activity (kerogen, bitumen, and lignines). The formation of ferrous iron from the dissolution of iron in the reducing environment created by bacterial degradation has also been observed. ${ }^{51}$ Knowledge of the processes that rule the alteration of material and the accumulation and growth of colloidal biofilms is very scarce. As a consequence, predictive capability in this area is extremely limited. ${ }^{52}$

\section{DISCUSSION AND SUMMARY}

It is clear that introduced materials can modify the quantity and character of colloids and their behavior within a repository in varied and complex ways. The sheer quantity in which some of the materials could be introduced and their potential proximity to the waste packages suggests that in some cases the introduced component may be the most important consideration in the prediction of species migration due to colloids. Some introduced materials that deserve consideration are: inorganic complexants (e.g., some components from batteries), organic complexants and nutrients for microbes (e.g., alcohol, antifreeze, bituminous materials, diesel fuel, hydrocarbons, some gases, clothes, lubricants, plastic, and wood), and groundwater pH modifiers (e.g., acids, concrete, grout, lime, and plaster). Sorption mechanism depends on the type of ion sorbed. As for colloid fromation, effects are specific to the identity of the chemical species, the $\mathrm{pH}$ and the redox state of the ions. In addition, whereas reversible adsorption can be modeled fairly well, desorption kinetics are not understood. Therefore, we require further system specific studies.

Whether the effects of these materials are positive or negative for the longevity of a repository remains to be determined. However, we do know that conditions that favor long range migration of colloids are low ionic strength, low temperature, anoxic conditions, high organic content, high flow velocities, high colloid concentrations, and sorption reduction by changes in water chemistry. Often low $\mathrm{pH}$ can also favor long range migration. Because the relationships are complex and interdependent, the effects of many repository materials have yet to be ascertained. Thermochemical and kinetic data are required to model the multiple and interdependent factors in colloid formation. Efforts to address the formation of soluble ionic species or complexes and the consequent formation of colloids need to address coupled effects. 
A number of effects are not well documented, but are essential to the prediction of colloid effects in a repository setting. These include the release of nuclides as anions or in association with inorganic (silicate, aluminate) and organic complexes, the interactions between colloids that influence their relative stabilities, and the coupled effects of $\mathrm{pH}$, ionic strength, competing ions, temperature, and adsorbate concentration. ${ }^{36}$ Research activity is shifting from laboratory column experiments to interpretation of field data and to modeling efforts ${ }^{10}$ in order to elucidate coupled effects and thus increase the reliability of large scale modeling efforts.

\section{ACKNOWLEDGMENTS}

This review represents the initial phase of one aspect of a general investigation into the chemical consequences of introduced materials on the post-emplacement environment, which is the responsibility of the Man-made Materials task of the Yucca Mountain Site Characterization Project. The work is performed under the auspices of the U.S. Dept. of Energy by Lawrence Livermore National Laboratory under contract W7405-ENG-48.

\section{REFERENCES}

1. K. A. West, LA-11398-MS, Los Alamos National Laboratory (1988).

2. Meike and Wittwer, Focus ' 93 (1993) in press.

3. J. F. McCarthy and J M. Zachara, Envi. Sci. Tech. 23 (1989).

4. D. C. Agrawal, R. Raj, and C. Cohen, "Nucleation of flocs in dilute colloidal suspensions", J. Amer. Ceram. Soc. 72 (1989).

5. B. G. Ershov and N. L. Sukhov, Radiat. Phys. Chem. 36 (1990).

6. W. B. Mills and S. Liu, Literature Review and Conceptual Model Development for Colloid/Metals Transport (COMET) Model in Porous Media, Tetra Tech Inc., Lafayette, California, Contract No. 68-03-3513, for EPA and AQUA TERRA CONSULTANTS (1989).

7. L. Carlson and U. Schwertmann, Geochim. Cosmochim. Acta 45, 421-429 (1981).

8. P. R. Anderson and M. M. Benjamin, Environ. Sci. Technol. 19 (11), 1048-1053 (1985).

9. R. M. Cornell, R. Giovanoli, and P. W. Schindler, Clays and Clay Minerals 35 (1), 21-28 (1987).

10. L. E. Fox, Geochim. Cosmochim. Acta 52, 771-777 (1988).

11. L. Liang, Thesis, California Institute of Technology, Pasadena, California (1988).

12. M. M. Benjamin and J. O. Leckie, J. Colloid Interface Sci. 79 (1), 209-221 (1981).

13 M. M. Benjamin and J. O. Leckie, J. Colloid Interface Sci. 83 (2), 410-419 (1981).

14. L. S. Balistrieri and J. W. Murray, Geochim. Cosmochim. Acta 46, 1253-1265 (1982).

15. C.-K. D. Hsi and D. Langmuir, Geochim. Cosmochim. Acta 49, 1931-1941 (1985).

16. K. A. Hunter, D. J. Hawke, and L. K. Choo, Geochim. Cosmochim. Acta 52, 627-636 (1988).

17. B. B. Johnson, Environ. Sci. Technol. 24 (1), 112-118 (1990).

18. L. S. Balistrieri and J. W. Murray, Geochim. Cosmochim. Acta 51, 1151-1160 (1987).

19. E. Matijevic, Properties of Colloidal Corrosion Products and their Effects on Nuclear Plants. Volume 1: Executive Summary, Electric Power Research Institute., NP-2606, Volume 1, Research Project 966-1 (1982).

20. E. Matijevic, Properties of Colloidal Corrosion Products and their Effects on Nuclear Plants. Volume 2, Electric Power Research Institute, NP-2606, Volume 2, Research Project 966-1 (1982).

21. E. Matijevic, Properties of Colloidal Corrosion Products and their Effect on Nuclear Plants, Electric Power Research Institute (1986). 
22. U. Olofsson, B. Allard, K. Andersson, and B. Torstenfelt, Formation and Properties of Radiocolloids in Aqueous Solution-A Literature St:rvey, Chalmers University of Technology, Sweden, Department of Nuclear Chemistry, Programrådet för radioaktivt avfall, Report Prav 4.25 (1981).

23. S. R. Jenkins, Environ. Sci. Technol. 7 (1), 43-47 (1973).

24. J. D. F. Ramsay, The Role of Colloids in the Release of Radionuclides from Nuclear Waste, AERE Harwell, AERE-R11823 (1985).

25. M. P. Gardiner, A. J. Smith, and S. J.Williams, In Manteo III: Concepts in Manipulating Groundwater Colloids for Environmental Restauration, U.S. Department of Energy: Manteo, North Carolina (1990).

26. F. T. Ewart and S. J. Williams, A Literature Survey of the Possible Effects of Humic and Fulvic Acids on the Disposal of LLW and ILW, United Kingdom Atomic Energy Authority, Harwell, AERE R 12023 (1986).

27. J. D. F. Ramsay, Radiochim. Acta 44/45, 165-170 (1988).

28. M. D. Reynolds, Thesis, Massachusetts Institute of Technology, Cambridge, Massachusetts (1982).

29. R. Grauer, The Coordination Chemistry of Humic Substances, NAGRA, Switzerland, NAGRA Technical Report 89-08E (1989).

30. K. F. Hayes and W. J. Weber, in Manteo III: Concepts in Manipulating Groundwater Colloids for Environmental Restoration, Manteo, North Carolina, 1990 (U.S. Department of Energy, Washington, D.C.), platform and poster abstracts.

31. L. Carlsen, Basic Geochemical Research for Migration Studies. Radionuclide-Soil Organic Matter Interactions, Riso Laboratory, Denmark (1984).

32. S. Boggs, D. Livermore, and M. G. Seitz, Humic Substances in Natural Waters and their Complexation with Trace Metals and Radionuclides, A Review, Argonne National Laboratory, Argonne, Ilinois, ANL-84-78 (1985).

33. J. O. Davis, Geochim. Cosmochim. Acta 46, 2381-2393 (1982).

34. B. Allard, I. Àrsenie, H. Borne, J. Ephraim, G. Gardhammar, and C. Pettersson, Isolation and Characterization of Humics from Natural Waters, SKB, SKB 90-27 (1990).

35. G. Bidoglio, A. Avogadro, and A. De Plano, in Scientific Basis for Nuclear Waste Management IX, Stockholm, Sweden, 1985, edited by L. O. Werme (Mater. Res. Soc. Proc., Pittsburgh, Pennsylvania), Vol. IX, pp. 709-716.

36. A. L. Sanchez, J. W. Murray, and T. H. Sibley, Geochim. Cosmochim. Acta 49, $2297-$ 2307 (1985).

37. K. H. Lieser, B. Gleitsmann, S. Peschke, and T. Steinkopff, Radiochim. Acta 40, 39-47 (1986).

38. R. W. Buddemeier and J. R. Hunt, Appl. Geochem. 3, 535-548 (1988).

39. T. C. Maiti, M. R. Smith, and J. C. Laul, Nuclear Technol. 84, 82-87 (1989).

40. P. Seyler and J.-M. Martin, Environ. Sci. Technol. 23 (10), 1258-1263 (1989).

41. J. Buffle, R. R. De Vitre, D. Perret, and G. G. Leppard, Geochim. Cosmochim. Acta 53, 399-408 (1989).

42. O. Weres, A. Yee, and L. Tsao, J. Colloid Interface Sci. 84 (2), 379-402 (1981).

43. W. Stumm, H. Hueper, and R. L. Champlin, Curr. Res. 1 (3), 221-227 (1967).

44. A. Avogadro and G. De Marsily, in Scientific Basis for Nuclear Waste Management VII, Boston, Massachusetts, 1984, edited by G. L. McVay (Elsevier Science Publishing Company, New York), pp. 495-505 (1984).

45. R. J. Kuo and E. Matijevic, J. Colloid Interface Sci. 78 (2), 407-419 (1980).

46. C. Petersson, J. Ephraim, B. Allard, and H. Boren, Characterization of Humic Substances from Deep Groundwaters in Granitic Bedrock in Sweden, SKB, Stockholm, Sweden, SKB Technical Report 90-29 (1990).

47. G. Longworth and M. Ivanovich, in Manteo III: Concepts in Manipulating Groundwater Colloids for Environmental Restoration, Manteo, North Carolina, 1990 (U.S. Department of Energy, Washington, D.C.), platform and poster abstracts. 
48. M. A. Anderson, M. I. Tejedor-Tejedor, and R. R. Stanforth, Environ. Sci. Technol. 19 (7), 632-637 (1985).

49. T. Dabros and T. G. M. Van De Ven, J. Colloid Interface Sci. 89 (1), 232-244 (1982).

50. M. A. Scholl and R. W. Harvey, In Manteo III: Concepts in Manipulating Groundwater Colloids for Environmental Restoration, U.S. Department of Energy: Manteo, North Carolina (1990).

51. P. M. Gschwend and M. D. Reynolds, J. Contaminant Hydrol. 1, 309-327 (1987).

52. J. R. Hunt, in Manteo III: Concepts in Manipulating Groundwater Colloids for Environmental Restoration, Manteo, North Carolina, 1990 (U.S. Department of Energy, Washington, D.C.), platform and poster abstracts. 

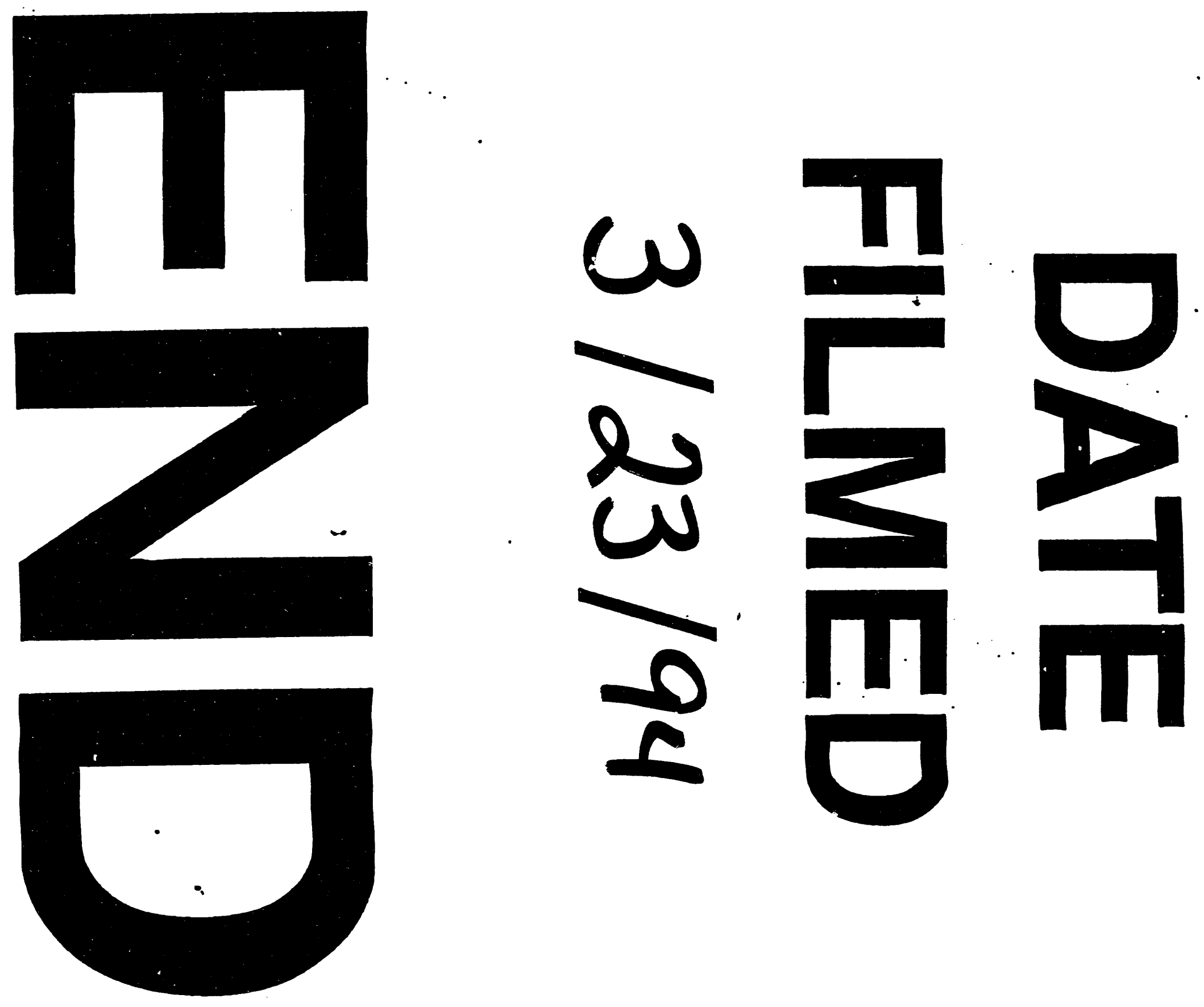
